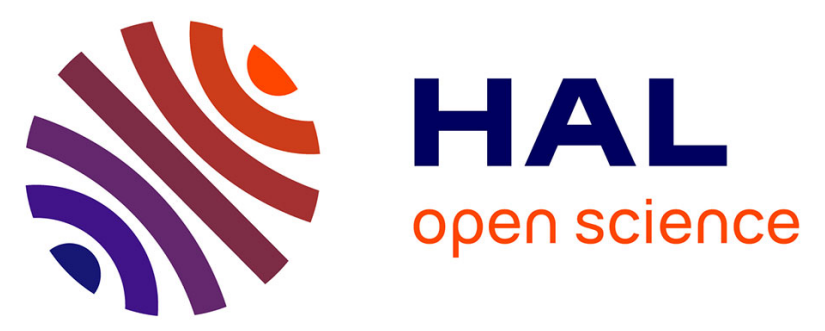

\title{
A DESIGN OF LIQUID CRYSTAL MATERIAL FOR MULTIPLEXED LIQUID CRYSTAL DISPLAY
}

\author{
K. Toriyama, K. Suzuki, T. Nakagomi, T. Ishibashi, K. Odawara
}

\section{To cite this version:}

K. Toriyama, K. Suzuki, T. Nakagomi, T. Ishibashi, K. Odawara. A DESIGN OF LIQUID CRYSTAL MATERIAL FOR MULTIPLEXED LIQUID CRYSTAL DISPLAY. Journal de Physique Colloques, 1979, 40 (C3), pp.C3-317-C3-321. 10.1051/jphyscol:1979361 . jpa-00218757

\section{HAL Id: jpa-00218757 https://hal.science/jpa-00218757}

Submitted on 1 Jan 1979

HAL is a multi-disciplinary open access archive for the deposit and dissemination of scientific research documents, whether they are published or not. The documents may come from teaching and research institutions in France or abroad, or from public or private research centers.
L'archive ouverte pluridisciplinaire HAL, est destinée au dépôt et à la diffusion de documents scientifiques de niveau recherche, publiés ou non, émanant des établissements d'enseignement et de recherche français ou étrangers, des laboratoires publics ou privés. 


\title{
A DESIGN OF LIQUID CRYSTAL MATERIAL FOR MULTIPLEXED LIQUID CRYSTAL DISPLAY
}

\author{
K. TORIYAMA, K. SUZUKI, T. NAKAGOMI, T. ISHIBASHI and K. ODAWARA \\ Electron Tube Division, HITACHI, LTD., 3300 Hayano, Mobara, Chiba, Japan
}

\begin{abstract}
Résumé. - On décrit une méthode permettant d'obtenir un matériel liquide cristallin adapté au multiplexage d'affichages à structure nématique tordue. Un bon fonctionnement du multiplexage est conditionné par la compensation de la forte dépendance angulaire de l'observation, du glissement de la tension de seuil avec la température et de la réponse peu satisfaisante à basse température.

On a réalisé un mélange composé de cristaux liquides à anisotropie diélectrique négative et positive (ester). Le développement intégré de la technique d'alignement moléculaire confirme que le mélange peut être employé dans des affichages à cristaux liquides de faible tension, $3 \mathrm{~V}$, avec un taux de multiplexage de $3: 1$.
\end{abstract}

\begin{abstract}
A design of liquid crystal material suitable for multiplexed twisted nematic liquid crystal displays has been described. For a satisfactory operation of multiplexing drive, it is necessary to compensate strong angular dependence of the viewing characteristics, drift of threshold voltage with temperature, and dull response at low temperature.

A liquid crystal mixture consists of dielectrically negative liquid crystal and dielectrically positive (ester) liquid crystal is designed. With the integrated development of molecular alignment technique, it is confirmed that the material is useful for low voltage, $3 \mathrm{~V}, 1: 3$ multiplexed liquid crystal displays.
\end{abstract}

1. Introduction. - A low voltage multiplexing drive of a twisted nematic liquid crystal display (TN-LCD) is not always obtained without the need for some technical compromise.

Some of the problems for such a display are limited operating voltage, narrow viewing angle, need of parallel molecular alignment, etc. In this paper, we present a design of liquid crystal (LC) material suitable for multiplexed TN-LCDs, such as in wrist watches, calculators, and matrix displays for computer terminals.

Satisfactory operation of multiplexing drive requires the solution of technical problems which relate to LC material to be used. These include strong angular dependence of the viewing characteristics, slow transient response time at low temperature, and drift of threshold voltage with temperature. Furthermore, for the best use of LCD, it is necessary to use low threshold voltage material for saving power of display systems. Matching LC materials to molecular alignment techniques, and vice versa, we have obtained a new LC material system for the 3 volt, $1: 3$ multiplexing drive.

2. Performance parameter and design outline of TN-LCD for multiplexing drive. - In the multiplexing drive of a TN-LCD [1], the variation of optical response of the threshold voltage is very important. The factors limiting operating voltage tolerance, in addition to temperature dependence of the threshold voltage, are threshold sharpness and viewing angle dependence of the threshold voltage.

The operating voltage tolerance in a TN-LCD in the case of the $1: 3$ multiplexing drive as shown in figure 1 is given by

$$
V_{\mathrm{thL}}+\Delta V_{\mathrm{thL}} \leqq V_{\mathrm{o}} \leqq V_{\mathrm{thH}}-\Delta V_{\mathrm{thH}}
$$

where $V_{\text {thL }}$ and $V_{\mathrm{thH}}$ are variation values of threshold voltage due to mass production and due to degradated life. For an evaluation of molecular alignment technique and LC materials, we give a definition of performance parameter for multiplexed TN-LCDs. The relations between threshold voltage and viewing angle in a TN-LCD are shown in figure 2. The operating region of the device is enclosed within the solid lines in figure 2 due to the following limitations :

1) There are restrictions on drive voltage due to crosstalk problems in multiplexing drives, as illustrated in figure 1.

2) An operating temperature range as narrow as 0 to $40^{\circ} \mathrm{C}$ may be acceptable. Therefore, the operating 


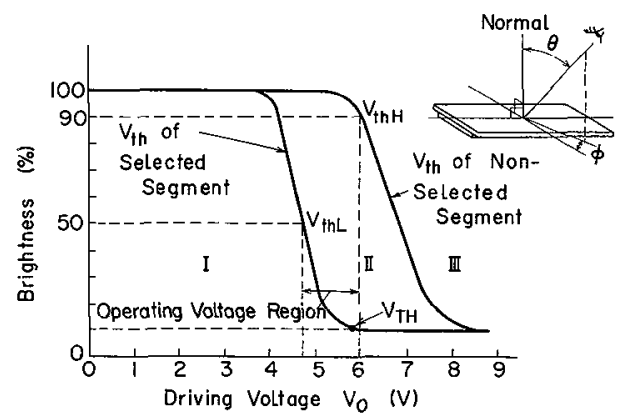

FIG. 1. - Brightness curve of a TN-LCD in the case of the $1: 3$ selection multiplexing drive. The applied voltage signals are given on the right side $\left(\phi=0^{\circ}, \theta=0^{\circ}, T=25^{\circ} \mathrm{C}\right.$, tilt angle $\left.\varphi=3^{\circ}\right)$ Region I : $O F F$ state; Region II : $O N$ state on selected segment ; Region III : $O N$ state on non-selected segment due to crosstalk.

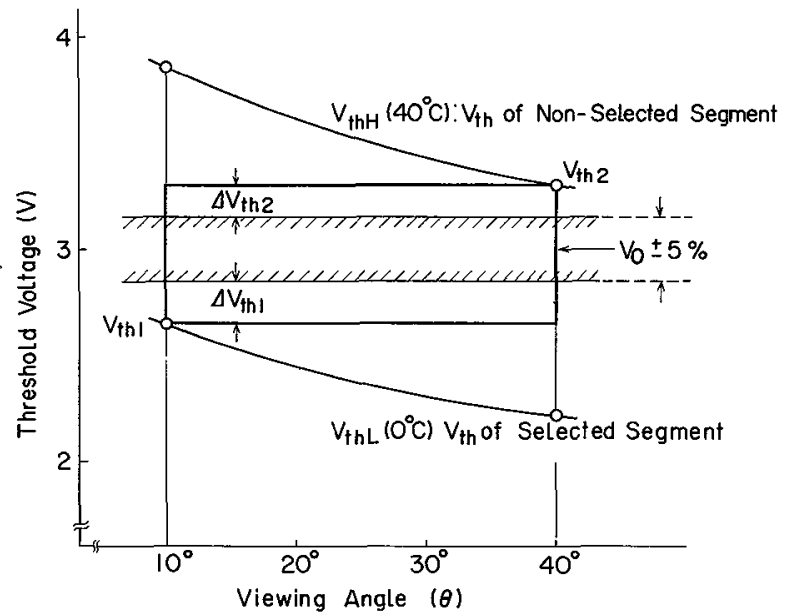

FIG. 2. - Curves of threshold voltage vs. viewing angle. $V_{0}$ : operating voltage, $\Delta V_{\mathrm{thL}}, \Delta V_{\mathrm{thH}}$ : variation due to mass-production and degraded life $\Delta V_{\text {th1 } 1}, \Delta V_{\text {th2 }}$ : error margin.

voltage region is limited between $V_{\mathrm{thL}}$ at $0{ }^{\circ} \mathrm{C}$ and $V_{\text {thH }}$ at $40^{\circ} \mathrm{C}$.

3) A viewing angle as narrow as $10^{\circ}$ to $40^{\circ}$ may be acceptable.

Therefore, the operating voltage region is enclosed within the solid lines in figure 2. $\Delta V_{\mathrm{th} 1}$ is the error margin of $V_{\text {thL }}$ at $0^{\circ} \mathrm{C}$ and $10^{\circ}$ viewing angle. $\Delta V_{\text {th2 }}$ is the error margin of $V_{\mathrm{thH}}$ at $40^{\circ} \mathrm{C}$ and $40^{\circ}$ viewing angle.

Thus, the figure of merit for a liquid crystal material under a given molecular alignment technique can be defined as follows :

Figure of merit :

$$
\begin{aligned}
M & =\frac{V_{\mathrm{thH}}\left(40^{\circ} \mathrm{C}, \theta=40^{\circ}\right)^{\circ}-V_{\mathrm{thL}}\left(0^{\circ} \mathrm{C}, \theta=10^{\circ}\right)}{V_{\mathrm{thH}}\left(40^{\circ} \mathrm{C}, \theta=40^{\circ}\right)+V_{\mathrm{thL}}\left(0^{\circ} \mathrm{C}, \theta=10^{\circ}\right)} \\
& =\frac{1-\left(\gamma / V^{\theta}\right)\left[1 /\left(\alpha . \Delta V^{\mathrm{T}}\right)\right]}{1+\left(\gamma / V^{\theta}\right)\left[1 /\left(\alpha . \Delta V^{\mathrm{T}}\right)\right]}
\end{aligned}
$$

where

$$
\gamma=\frac{V_{\mathrm{thL}}\left(0^{\circ} \mathrm{C}, \theta=10^{\circ}\right)}{V_{\mathrm{TH}}\left(0^{\circ} \mathrm{C}, Q=10^{\circ}\right)}
$$

$$
\begin{aligned}
\alpha & =\frac{V_{\mathrm{thH}}\left(0^{\circ} \mathrm{C}, \theta=40^{\circ}\right)}{\nabla_{\mathrm{TH}}\left(0^{\circ} \mathrm{C}, \theta=40^{\circ}\right)} \\
\Delta V^{\theta} & =\frac{V_{\mathrm{thH}}\left(0^{\circ} \mathrm{C}, \theta=40^{\circ}\right)}{V_{\mathrm{thH}}\left(0^{\circ} \mathrm{C}, \theta=10^{\circ}\right)} \\
\Delta V^{\mathrm{T}} & =\frac{V_{\mathrm{thH}}\left(40^{\circ} \mathrm{C}, \theta=40^{\circ}\right)}{V_{\mathrm{thH}}\left(0^{\circ} \mathrm{C}, \theta=40^{\circ}\right)} .
\end{aligned}
$$

Here we also definate $M_{\mathrm{T}}$ :

$M_{\mathrm{T}}=\frac{V_{\mathrm{thH}}\left(0^{\circ} \mathrm{C}, \theta=40^{\circ}\right)-V_{\mathrm{thH}}\left(40^{\circ} \mathrm{C}, \theta=40^{\circ}\right)}{V_{\mathrm{thH}}\left(0^{\circ} \mathrm{C}, \theta=40^{\circ}\right)+V_{\mathrm{thH}}\left(40^{\circ} \mathrm{C}, \theta=40^{\circ}\right)}$.

3. Molecular alignment in TN-LCD. - The technology of molecular alignment has much influence on multiplexed display performance [1].

A technique applicable to any LC material and suitable for mass production is required which reliably provides uniform quiescent alignment and is free from induced domains of reverse tilt. To develop such a process, we have investigated an alignment technique in which alignment forces are produced by the rubbed surface of a special film.

For a multiplexing drive, it is essential that near planar alignment, or low tilt alignment, be realized. To achieve and verify a process for near planar alignment, we developed a measuring technique for accurate detection of low tilt angles of LC molecules in the device. This technique, which we named "critical magneto-capacitive method" to be distinguished from previous methods [2], is based on measuring the critical threshold magnetic field for reorientation of $\mathrm{LC}$ molecules which are at right angles to the magnetic field.

LC molecules are aligned homogeneously by an alignment technique. The cell is positioned referring to rotation angle $\left(\theta_{i}\right.$ around the axis perpendicular to both the alignment direction and the magnetic field as shown in figure 3. The state of LC orientation is inferred from observation of the capacitance of the cell at each location of angle $\left(\mathbb{A}_{\mathrm{i}}\right.$ under the scanned magnetic field strength.

A prominent value of threshold magnetic field $\left(H_{\mathrm{c}}\right)$ is observed with a slight rotation of the cell near specified angle $(\mathbb{A})_{i}^{*}$ as shown in figure 3 . The angle $(\mathbb{A})_{\mathrm{i}}^{*}$ which gives the apex in the $H_{\mathrm{c}}-\mathbb{A}_{\mathrm{i}}$ curve corresponds to the tilt angle of LC molecules. Both the reason for the appearance of the apex in the curve and the claim that $(\mathbb{A})_{i}^{*}$ corresponds to the tilt angle of LC molecules are elucidated by calculations based on Leslie's equation [3].

Thus the tilt angle is determined completely by geometrical configuration without using fitting procedures. This method ensures 0.1 degree accuracy.

In the developed device, directors are all tilted $3 \pm 1$ degrees in the same direction in the OFF state over the patterned electrodes, and this ensures freedom from induced domains of reverse tilt in the ON state. 

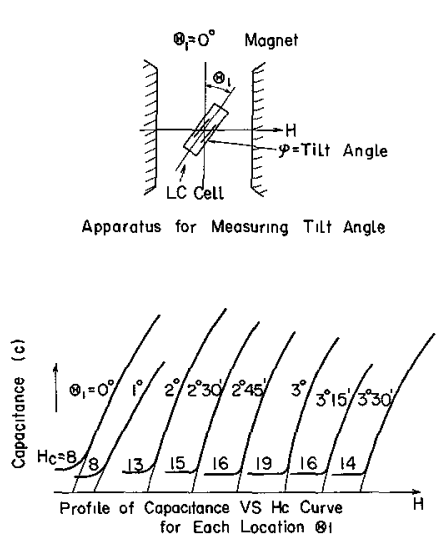

FIG. 3. - Measuring method for accurate detection of low tilt angle of liquid crystal molecules.

4. Design of liquid crystal material for multiplexing. - 4.1 DESIGN OUTLINE OF LIQUID CRYSTAL MATERIAL. - In developing liquid crystal materials, the following problems were encountered :

1) Temperature dependence of the threshold voltage.

2) Viewing angle dependence of the threshold voltage.

3) Decreasing tendency of figure of merit (M) corresponding to the lowering of the threshold voltage of the LC.

4) Maintenance of a wide mesomorphic range.

5) Dull response at low temperature.

We investigated various LC materials focusing on factors of figure of merit, $\Delta V^{\mathrm{T}}, \Delta V^{\theta}$ and $\gamma$. LC materials consisting of dielectrically positive $(\mathrm{Np})$ type molecules (Group I) have been rejected because of either their large threshold voltage drift with temperature or their poor $\Delta V^{\theta}$ values, while some materials among LCs consisting of mixtures of dielectrically negative material $(\mathrm{Nn})$ and dielectrically positive material $(\mathrm{Np})$ give a good figure of merit.

For a design of low threshold material, we must use a larger quantity of dielectrically positive materials, which often causes a rise of crystal-nematic transition temperature, increase of viscosity, and increase of temperature dependence of threshold voltage. To compromise those conflictions and to find out ideal materials, we have searched among possible materials referring to their physical properties, such as dielectric anisotropy, elastic constants, and optical anisotropy.

4.2 TEMPERATURE DEPENDENCE OF THRESHOLD VOLvOLTAGE. - Temperature dependence of the optical threshold voltage $V_{\mathrm{th}}$ is a dominant factor in the figure of merit (M). We have tried to analyze the relations between $\Delta V^{\mathrm{T}}$ or $M_{\mathrm{T}}$ and $\mathrm{LC}$ material properties or molecular structures. An analytical expression for the temperature dependence of voltage threshold is given by F. J. Kahn et al. [4] as follows :

$$
\begin{gathered}
V_{\mathrm{th}} \propto S^{1 / 2}(A / T+B)^{-1 / 2} V^{-7 / 6} \times \\
\times\left(C_{\mathrm{ii}}+(1 / 4) .\left(C_{33}-2 C_{22}\right)+2 C_{22}(L / P)\right)^{1 / 2} \\
C_{\mathrm{ii}}=K_{\mathrm{ii}} V^{7 / 3} / S^{2}
\end{gathered}
$$

where

$S=$ order parameter, $V=$ molar volume,

$L=$ LC layer thickness, $p=$ LC pitch,

$K_{\mathrm{ii}}=$ Frank elastic constant.

From equation (8), we have the following equation :

$$
\begin{aligned}
& \left(1 / V_{\mathrm{th}}\right)\left(\mathrm{d} V_{\mathrm{th}} / \mathrm{d} T\right)=1 / 2(1 / S)(\partial S / \partial T) \\
& \quad+\frac{(-1 / 2)}{(A / T+B)} \partial(A / T+B) / \partial T \\
& \quad+(-7 / 6)(1 / V) \partial V / \partial T+\left(-1 / C_{\mathrm{ii}}\right) \partial C_{\mathrm{ii}} / \partial T
\end{aligned}
$$

we have evaluated each component of equation (10) :

1) $C_{\mathrm{ii}}:$ From the definition of themselves, $\partial C_{\mathrm{ii}} / \partial T=0$.

2) $V=M / d$ : The temperature dependence of density $(d) ;(-1 / d)(\partial d / \partial T)$ of most LC materials is of the order of $-8 \times 10^{-4}$, which is a minor factor of the right side of equation (10).

3) $(A / T+B)$ : Since in most LC materials, $\mathrm{A}$ is almost equal to $10^{3} \mathrm{~B}$, the contribution of this factor to the right side of equation (10) is of the order of $1.5 \times 10^{-3}$.

4) Order parameter $(S)$ : From the above consideration and investigation of temperature dependence of order parameter of LC, such as Schiff base, azoxy, ester, biphenyl, and cyclohexane-ring-containing LC, the most important factor of $\left(1 / V_{t h}\right)\left(\mathrm{d} V_{t h} / \mathrm{d} T\right)$ is obviously the factor $(1 / S)(\partial S / \partial T)$ on the right side of equation (10).

Azoxy LC is the best material for suppression of drift of $V_{\text {th }}$ with temperature, while biphenyl is the worst (Table I).

We are tempted to conclude that LC material with a small $\partial S / \partial T$ and large $S$ has a small temperature dependence of threshold voltage. We must notice in table I that HN-1 (Hitachi developed LC) has a small $(1 / V)(\mathrm{d} V / \mathrm{d} T)$ value, though the $\mathrm{LC}$ itself has a large $(1 / S)(\partial S / \partial T)$ value comparable to that of biphenyl. The formulation of $V_{\text {th }}$ as a function of order parameter $\mathrm{S}$ should be studied further.

In relation to physical constants; viz., dielectric anisotropy and elastic constants, which govern the threshold voltage of LC, we have made another investigation of temperature dependence of $V_{\text {th }}$ for each LC :

$$
\begin{aligned}
& \left(1 / V_{\mathrm{th}}\right)\left(\mathrm{d} V_{\mathrm{th}} / \mathrm{d} T\right) \propto\left(1 / V_{\mathrm{th}}^{*}\right)\left(\mathrm{d} V_{\mathrm{th}}^{*} / \mathrm{d} T\right)= \\
& \quad=(1 / 2)(1 / K)(\partial K / \partial T)-(1 / 2)(1 / \Delta \varepsilon) \times(\partial \Delta \varepsilon / \partial T)
\end{aligned}
$$

where

$V_{\mathrm{th}}=$ optical threshold voltage,

$V_{t h}^{*}=$ electrical threshold voltage,

$K=K_{1}+(1 / 4)\left(K_{3}-2 K_{2}\right)$. 
TABLE I

Temperature dependence of $V_{\mathrm{th}}$ and order parameter

\begin{tabular}{|c|c|c|c|c|c|}
\hline & $(1)$ & $(2)$ & $(3)$ & $(4)$ & $(5)$ \\
\hline $\begin{array}{c}\text { Factors } \\
\text { Material }\left(10^{-3}\right)\end{array}$ & $\frac{1}{V_{t h}} \frac{d V_{\text {th }}}{d T}$ & $\frac{1}{S} \frac{\partial S}{\partial T}$ & $T^{-1}$ & $\frac{1}{V} \frac{\partial V}{\partial T}$ & $\frac{1}{2}(2)-\frac{1}{2}(3)-\frac{7}{6}(4)$ \\
\hline Azoxy & -34 & -5.6 & 3 & 0.8 & -05 \\
\hline $\begin{array}{c}\text { Schiff Base } \\
\text { (Np. TN-200) }\end{array}$ & -48 & -64 & 3 & 08 & 0 \\
\hline $\begin{array}{c}\text { Schiff Base } \\
\text { (Nn +Np) }\end{array}$ & -7 & -8 & 3 & 08 & -16 \\
\hline \begin{tabular}{c} 
Ester \\
\hline $\begin{array}{c}\text { Biphenyl } \\
\text { (E-7) }\end{array}$
\end{tabular} & -5 & -8 & 3 & 08 & -16 \\
\hline CN-Phenyl Cyionexane & -5 & -59 & 3 & 0.8 & -06 \\
\hline HN-1 & -45 & -94 & 3 & 08 & -23 \\
\hline
\end{tabular}

We have measured each term of equation (11) using a method developed by one of the authors. A small temperature dependence of $V_{\mathrm{th}}$ could be realized if an effective cancellation between the 1 st and 2 nd terms of the right side of equation (11) takes place. Good cancellation is realized in $\mathrm{HN}-1$, while in biphenyl (E-7) and in cyanophenylcyclohexane (ZLI-1132), the cancellation is poor. For azoxy, though it has a small temperatur dependence of $V_{t h}$, the cancellation is rather insufficient. This confliction remains to be investigated further (Table II).

\section{TABLE II}

Temperature dependence of threshold voltages and physical constants, $\Delta \varepsilon$ and $K$

\begin{tabular}{|c|c|c|c|c|}
\hline & (1) & (2) & (3) & $(2)+(3)$ \\
\hline $\begin{array}{l}\text { Factors } \\
\text { Material }\end{array}$ & $\frac{1}{V_{t h}} \frac{d V_{t h}}{d T}$ & $\frac{1}{2} \frac{1}{K} \frac{\partial K}{\partial T}$ & $-\frac{1}{2} \frac{1}{\Delta \epsilon} \frac{\partial \Delta \epsilon}{\partial T}$ & \\
\hline Azoxy & -34 & -13.3 & 47 & -86 \\
\hline $\begin{array}{l}\text { Schiff Bose } \\
\text { (Np, TN-2OO) }\end{array}$ & -4.8 & -68 & 36 & -32 \\
\hline $\begin{array}{c}\text { Biphenyl } \\
(E-7)\end{array}$ & -81 & -114 & 2.9 & -85 \\
\hline $\begin{array}{c}\text { Gyano Phenyl Cylohexane } \\
\text { (ZLI - II32) }\end{array}$ & -50 & -78 & 24 & -54 \\
\hline $\mathrm{HN}-\mathrm{I}$ & -45 & -91 & 44 & -47 \\
\hline
\end{tabular}

4.3 THRESHOLD SHARPNESS AND VIEWING ANGLE DEPENDENCE OF $V_{\text {th }}$ - A decreasing tendency of figure of merit $(\mathrm{M})$ corresponding to the reduction of $V_{\text {th }}$ of LC materials is found. For azoxy and Schiff base (Nn plus Np), as a example, the tendency is shown in figure 4. Our explanation of this phenomenon is as follows : large dielectric anisotropies of LCs which are necessary' for reducing threshold voltage should have an adverse effect on the transmission curve, making it less steep. This may be a consequence of the relative decrease of electric field in the center of the layer of the device, where the

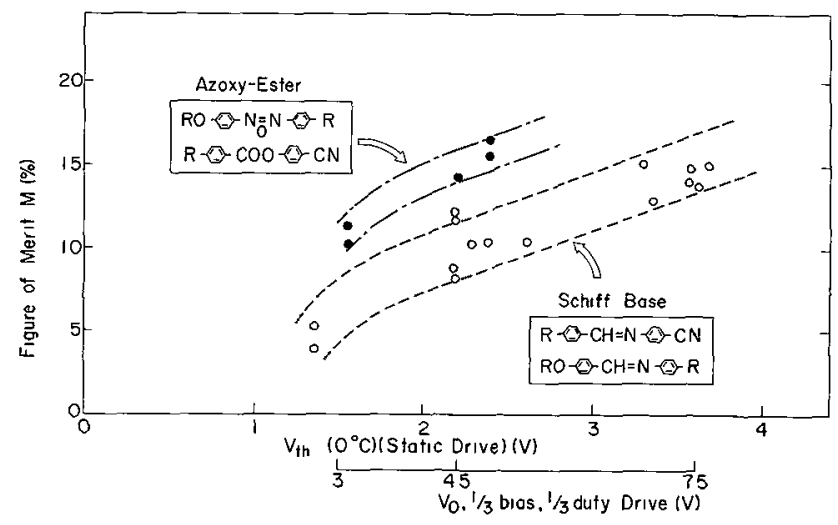

Fig. 4. - Relation between figure of merit (M) and threshold voltage of liquid crystal materials.

effective dielectric constant is larger. The experimental results suggest that the reducing of $V_{\text {th }}$ of $\mathrm{LC}$ has a strong correlation not to threshold sharpness but to the factor $\gamma / \Delta V^{\theta}$ as shown in figure 5. The mechanisms of the correlation between $V_{\text {th }}(\Delta \varepsilon)$ and the factor $\gamma / \Delta V^{\theta}$ are not understood yet.

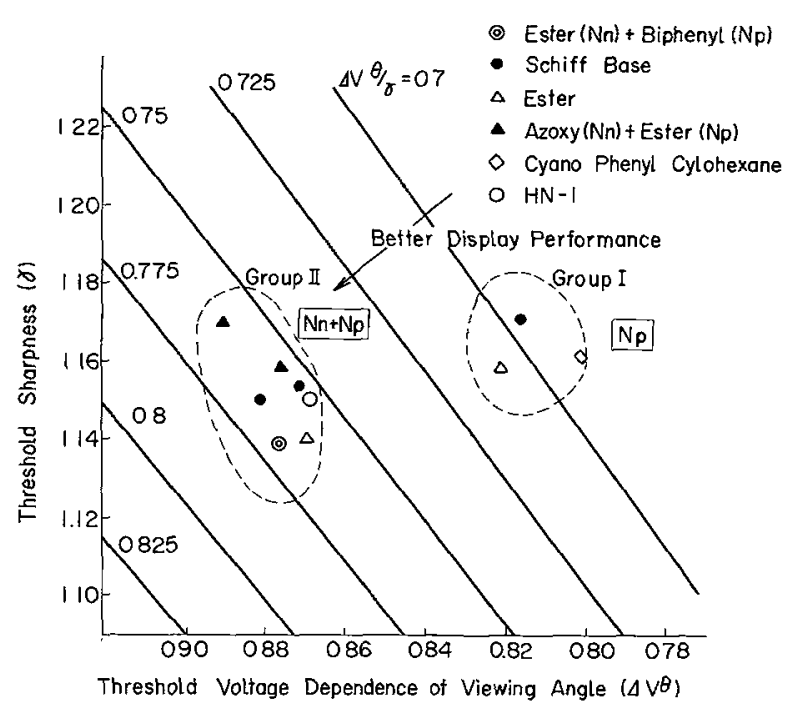

Frg. 5. - Properties $\gamma, \Delta V^{\theta}$ in various LC materials. Nn : Dielectrically negative LC. $\mathrm{Np}$ : Dielectrically positive LC.

Anyhow, the decreasing tendency of figure of merit (M) corresponding to the lowering of the $V_{\mathrm{th}}$ of LC is an obstacle to the development of LC materials. We studied various $L C$ materials focusing on $\Delta V^{\theta}$ and $\gamma$. We know by experience that $L C$ consisting of dielectrically positive ( $\mathrm{Np}$ ) type molecules (Group I) have poor $\Delta V^{\theta}$ values, while LCs consisting of mixtures of dielectrically negative material $(\mathrm{Nn})$ and dielectrically positive material (Np) (Group II) give good $\Delta V^{\theta}$ values as shown in figure 5.

4.4 CONTROL OF $V_{\text {th }}$ AND MESOMORPHIC RANGE. From the above results and preliminary experimental results, we have selected a Nn plus $\mathrm{Np}$ system which fulfills the following criteria : 
1) An Np nematic LC or nematogenic material which has a high solubility in Nn LC.

2) An LC which gives the composed system a wide operating tolerance : or a system which has a small temperature dependence of the threshold voltage.

According to the criteria, we have developed an $\mathrm{Nn}$ plus $\mathrm{Np}$ mixture system. Miscibility or alloying of $\mathrm{Np}$ to $\mathrm{Nn}$ becomes poor in propertion to an increase of the quantity of $\mathrm{Np}$. In many binary systems of $\mathrm{Nn}$ plus Np, crystal-nematic transition temperature (C-N point) markedly rises as the quantity of $\mathrm{Np}$ component increases. To solve this alloy problem or C-N temperature problem, we have two kinds of approaches :

1) A study of ternary-system $\mathrm{Nn}-\mathrm{N}_{\mathrm{n}}^{\mathrm{p}}-\mathrm{Np}$ to construct a stable low threshold voltage LC materials. Heare the symbol $\mathrm{N}_{n}^{\mathrm{p}}$ means an LC material which is dielectrically negative but contains an electrically polar group in the molecular structure.

2) A study of substitution of $\mathrm{Np}$ by binary $\mathrm{N}_{\mathrm{p}}^{\mathrm{i}}$ plus $\mathrm{N}_{\mathrm{p}}^{\mathrm{j}}$ system.

Azoxy, through it has a good figure of merit as shown in figure 6, is omitted because it is easily degradated by light. In conclusion, we have selected a ternary mixture system $(\mathrm{HN}-1)$ of $\mathrm{Nn}, \mathrm{N}_{\mathrm{p}}^{1}$ (cyanoester) and $H_{p}^{2}$. Using the previous results, we have decided on the optimum quantity of each component.

5. The design of multiplexing. - The following design has been adopted in order to set up the production of a TN-LCD.

1) The $1: 3$ selection multiplexing drive shown in figure 1 has been adopted in order to obtain a wide tolerance for achieving acceptable display performance.

2) Low power consumption of the system has made possible the design of hand-held calculators using silver oxide cells.

Variation of the source voltage has been controlled within $\pm 5 \%$. The cross-hatched area in figure 2 is the region of circuit variation. The error margins of threshold voltage, $\Delta V_{\mathrm{th} 1}, \Delta V_{\mathrm{th} 2}$ are 0.20 and 0.15

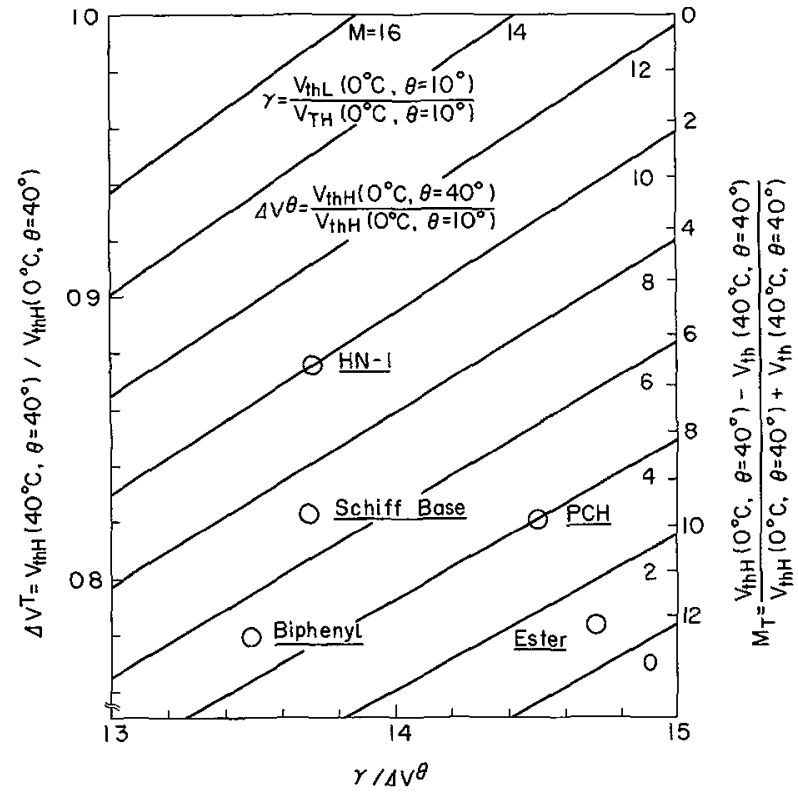

FIG. 6. - Relation between figure of merit and the factor $\gamma / \Delta V^{\theta}$.

respectively. $V_{\mathrm{th} 1}=2.65$ and $V_{\mathrm{th} 2}=3.30$ in figure 2 are the average values of TN-LCDs in production. We have made a worst-case evaluation for threshold voltage variation. The factors of threshold voltage variation are $\mathrm{LC}$ lot, process of $\mathrm{LC}$ charging to the cell, LC thickness, electrode resistance, tilt angle, and degradated life under accelerating test.

From our evaluation results, the variation values of threshold voltage $\Delta V_{\text {thL }}$ and $\Delta V_{\text {thH }}$ due to mass production and due to degraded life, are less than the error margins, $\Delta V_{\text {th } 1}$ and $\Delta V_{\text {th } 2}$. The contrast ratio, contaminants on electrode, gradual misalignment, and LC impedance were also evaluated. There is little evidence of deterioration of the TN-LCD.

6. Conclusion. - With the integrated development of material and molecular alignment technique, we have overcome difficulties in a design of TN-LCDs. We have made feasible the production of TN-LCDs with high quality and high reliability.

\section{References}

[1] a) Alt, P. M. and PLEShKo, P., «Scanning Limitations of Liquid-Crystal Displays ", IEEE Trans. Electron Devices ED-21 (1974) 46.

b) KAHN, F. J. and BurmeISTER, R. A., " Multiplexed Twisted Nematic Liquid Crystal Display $\$$, 1975 ; SID Int. Symp. Dig. Tech. Papers, April 22-24 1975, Washington, D.C., pp. 86-87.

c) Bigelow, J. E., Kashnow, R. A. and Stein, C. R., « Contrast Optimization in Matrix-Addressed Liquid Crystal Displays ", IEEE Trans. Electron Devices ED-22 (1975) 22.

d) Odawara, K., Ishibashi, T., Toriyama, K. and KanaZAKI, M., in Advances in Display Devices, ELECTRO 76, Boston, May 11-14, 1976

e) Goodman, L. A., Meyerhofer, D. and DiGiovanni, S., IEEE Trans, Electron Devices ED-23 (1976) 1176
[2] a) Batuer, G., Wrtter, V. and Berreman, D. W., Phys. Lett. 56A (1976) 142

b) KaHn, F. J., Mol. Crys. Liq. Cryst. 38 (1977) 109.

c) Toriyama, $\mathrm{K}$. and Ishibashi, $\mathrm{T}$., in Nonemissive Electrooptic Display, edited by A. R. Kmetz and F. K. von Willisen (Plenum, N.Y.) 1976.

d) Schefrer, T. J. and Nehring, J., J. Appl. Phys. 48 (1977) 1983.

e) Onnagawa, H. and Miyashita, K., Japan J. Appl. Phys. 13 (1974) 1741.

[3] Leslie, F. M., Mol. Cryst. Liq. Cryst. 12 (1970) 57.

[4] KaHN, F. J., in Nonemissive Electrooptic Display, edited by A. R. Kmetz and F. K. von Willisen (Plenum, N.Y.) 1976. 